\title{
Identidade Quilombola: Trajetória de um Conceito
}

\author{
Identidad Quilombola: Trajetoría de un Concepto \\ Quilombola Identity: Trajectory of a Concept
}

\author{
Lusinaide Cordeiro de Sales Lima Marques ${ }^{1}$ \\ Celiomar Emídio Martins ${ }^{2}$ \\ Uhênia Caetano Pereira ${ }^{3}$ \\ Marlon Cristhian Bellé Duarte 4 \\ Maria Margareth de Sousa dos Anjos ${ }^{5}$
}

\begin{abstract}
Resumo
Neste artigo faz-se a contextualização da formação histórica e social dos quilombos no Brasil. Apresentamos ainda, as trajetórias dos negros escravizados e a construção da cultura e identidade dos quilombos em Goiás, bem como, as características de comunidades tradicionais. Aspectos como a expressão cultural e as particularidades da religiosidade quilombola são analisados de forma qualitativa como fenômenos sociais que contribuem para formação identitária desses povos. Historicamente, após recorrentes tentativas de exploração dos indígenas para obtenção de mão de obra, os colonizadores portugueses optaram por escravizar os africanos trazendo-os para o Brasil com o objetivo de utilizar a força braçal dos negros na aquisição de riquezas. Esses escravos não eram escolhidos aleatoriamente, mas sim por terem habilidades que interessavam aos colonizadores. Contudo, apesar de disporem de uma estrutura social bem organizada, eles eram levados como cativos mesmo possuindo habilidades políticas e organizacionais. Uma significativa quantidade de negros viveram no Estado de Goiás durante o sistema escravista, estima-se que em 1750 havia cerca de 20 mil escravos em Goiás que, mesmo sendo submetidos à exploração e castigos diversos, trabalhavam principalmente nas minas contribuindo com a economia daquele período. Em algumas ocasiões até mesmo a acomodação era uma maneira de resistir e muitos escravos viviam de maneira "amigável" com seus senhores, podendo trabalhar, juntar riquezas, comprar alforrias, e até mesmo adquirir escravos.
\end{abstract}

Palavras-Chave: Cultura; Estrutura Social; Identidades; Quilombo.

\footnotetext{
1 Mestre em Ciências Sociais e Humanidades; Universidade Estadual de Goiás - Câmpus Minaçu; Minaçu, Goiás, Brasil; lusinaidecordeiro@gmail.com

${ }^{2}$ Especialista em Gestão ambiental; Universidade Estadual de Goiás - Câmpus Minaçu; Minaçu, Goiás, Brasil; celiomarga@hotmail.com

${ }^{3}$ Mestre em Natureza e Produção do Espaço; Universidade Estadual de Goiás - Câmpus Minaçu; Minaçu, Goiás, Brasil; uhenea@hotmail.com

${ }^{4}$ Especialista Metodologia de ensino e pesquisa na educação em história e Geografia do Brasil; Universidade Estadual de Goiás - Câmpus Minaçu; Minaçu, Goiás, Brasil; profmarloncristhian@ gmail.com

5 Especialista Geografia meio ambiente e turismo; Universidade Estadual de Goiás - Câmpus Minaçu; Minaçu, Goiás, Brasil; margasousa203@gmail.com
} 


\title{
Resumen
}

En este artículo hacemos la contextualización de la formación histórica y social de los quilombos en Brasil. En el caso de los negros esclavizados y la construcción de la cultura e identidad de los quilombos en Goiás, así como las características de las comunidades tradicionales, presentamos todavía las trayectorias de los negros esclavizados y la construcción de la cultura e identidad de los quilombos. Aspectos como la expresión cultural y las particularidades de la religiosidad quilombola son analizados de forma cualitativa como fenómenos sociales que contribuyen a la formación identitaria de esos pueblos. Históricamente, después de los intentos recurrentes de exploración indígenas para obtener mano de obra, los colonos portugueses eligió para esclavizar a los africanos que las pongan a Brasil con el fin de utilizar la fuerza manual de los negros en la adquisición de la riqueza. Estos esclavos no eran elegidos aleatoriamente, sino porque tenían habilidades que interesaban a los colonizadores. Sin embargo, a pesar de disponer de una estructura social bien organizada, ellos eran llevados como cautivos incluso poseiendo habilidades políticas y organizacionales. Una significativa cantidad de negros vivieron en el Estado de Goiás durante el sistema esclavista, se estima que en 1750 había cerca de 20 mil esclavos en Goiás que, aun siendo sometidos a la explotación y castigos diversos, trabajaban principalmente en las minas contribuyendo con la economía de aquel período. En algunas ocasiones incluso la acomodación era una manera de resistir y muchos esclavos vivían de manera "amigable" con sus señores, pudiendo trabajar, juntar riquezas, comprar alforrias, e incluso adquirir esclavos.

Palabras claves: Cultura, Estructura social, Identidad, Quilombo.

\begin{abstract}
In this article we contextualize the historical and social formation of quilombos in Brazil. We also present the trajectories of enslaved Negroes and the construction of the culture and identity of quilombos in Goiás, as well as the characteristics of traditional communities. Aspects such as the cultural expression and peculiarities of quilombola religiosity are analyzed in a qualitative way as social phenomena that contribute to the identity formation of these peoples. Historically, after recurrent attempts to exploit the natives to obtain labor, the Portuguese settlers chose to enslave the Africans by bringing them to Brazil with the purpose of using the black strength of the blacks in the acquisition of wealth. These slaves were not chosen randomly, but rather because they had abilities that interested the settlers. However, despite having a well-organized social structure, they were taken as captives even with political and organizational skills. A significant number of Negroes lived in the state of Goiás during the slave system, it is estimated that in 1750 there were about 20,000 slaves in Goiás who, although subjected to exploitation and various punishments, worked mainly in the mines contributing to the economy of that period. On some occasions even accommodation was a way of resisting and many slaves lived in a "friendly" way with their masters, being able to work, gather wealth, buy manumission, and even acquire slaves.
\end{abstract}

Keywords: Culture, Social Structure, Identities, Quilombo.

\section{Introdução}

Historicamente, após recorrentes tentativas de exploração dos indígenas para obtenção de mão de obra, os colonizadores portugueses optaram por escravizar os africanos trazendo-os para o Brasil com o objetivo de utilizar a força braçal dos negros na aquisição de riquezas. Segundo Fernandes (2014), em 1538 vieram as primeiras remessas de escravos para o Brasil.

Esses escravos não eram escolhidos aleatoriamente, mas sim por terem habilidades que interessavam aos colonizadores. Contudo, apesar de disporem de uma estrutura social bem organizada, eles eram levados como cativos mesmo possuindo habilidades políticas e 
organizacionais, como descrito por Raquel Oliveira (2001, p. 18),

cada um desses povos tinha uma cultura e um modo de vida próprios. Muitos deles viviam em civilizações altamente desenvolvidas, onde havia grandes cidades e onde reis poderosos exibiam o luxo de suas cortes e tinham uma cultura muito refinada. Os artesãos sabiam trabalhar os metais como ninguém e em sua arte as esculturas de ferro e de madeira entalhada eram maravilhosas.

Em disputas para conquistar novos impérios eram escravizados por outras etnias locais que os vendiam para os traficantes europeus. $\mathrm{O}$ tráfico de africanos visava, além de mãos de obra para as plantações e colheitas nas fazendas dos senhores de engenho, a obtenção de lucros para os colonizadores. Soares $(2013$, p. 111) diz que "os navios negreiros que aqui chegavam traziam mais do que braços escravos para trabalhar. Em seus porões, viajam também culturas, idiomas, religiões e técnicas".

Entretanto, não havia qualquer manifestação de respeito pela peculiaridade identitária dos negros escravizados. Eles eram considerados como mercadorias, em alguns casos, mercadorias valiosas, utilizadas para fazer transações financeiras. Ao chegarem ao território brasileiro viviam aprisionados, aglomerados com etnias diferentes da qual pertenciam, o que ocasionava distanciamento da família, da sua língua e costumes. Em condições precárias os escravizados eram obrigados a deixarem as suas crenças e forçados a praticar a religião cristã.

Ás vezes, mesmo antes de embarcar, eles eram batizados, recebendo um nome cristão, e isso bastava para que fossem considerados "convertidos" à fé dos seus senhores. Outras vezes eram batizados assim que desembarcavam nos portos do Brasil, em Pernambuco e na Bahia, antes de serem levados ao mercado de escravos de Recife ou Salvador (OLIVEIRA, 2001, p. 18).

Na tentativa de destituir sua identidade e toda sua herança cultural, ao cativo era imposta a cultura europeia, com o intuito de incorporar novas mentalidades. Na medida em que isso acontecia, o africano passava a ser somente um produto que podia ser comercializado. O negro, quando comparado aos índios brasileiros, era considerado pelos colonizadores como dócil. 
A arrogância portuguesa considerava o povo negro mais dócil se comparado às comunidades indígenas encontradas no Brasil, mas isso se devia ao fato deles estarem em um ambiente completamente estranho à sua cultura, rodeados por uma língua estranha e plantas e animais exóticos aos seus conhecimentos (FERNANDES, 2014, p. 18-19).

O fato de estar em desvantagem no conhecimento local, em fase de adaptação à cultura totalmente diferente, colocava-o em situação desfavorável e propiciava a dominação. Contudo, a resistência dos negros à brutalidade dos colonizadores proporcionou uma adequação cultural, logo, favoreceu a continuidade de suas tradições, divulgadas através da oralidade por gerações.

Além disso, a persistência dos negros em manter a sua identidade, desde os tempos coloniais, influenciou a cultura brasileira, seja através da dança, música, culinária, língua ou religião. Dessa forma, infere-se que temos uma herança africana que nutriu o multiculturalismo presente no Brasil, sobretudo no âmbito da religiosidade, permitindo assim uma (re)elaboração gradativa de singularidades, mesmo após os encontros culturais.

\section{Quilombo em Goiás}

Em Goiás, o provável caminho a ser percorrido para suprir a escravidão foi o Estado de Salvador, que passou a ser um ponto de mediação entre o Brasil e a África, situação que facilitava, sobretudo a intermediação dos diferentes povos. Nesse viés Loiola, (2008, p. 22) expressa que "esse movimento interligou as capitanias do interior do Brasil à África, não podendo ser visto apenas como tráfico interno". A autora acrescenta que:

\footnotetext{
Os escravizados, trazidos da Bahia no século XVIII eram escravos novos (de nação mina), em contrário aos do século XIX (quando prevaleceram os Angola), sinalizando que a dinâmica da escravidão em Goiás estava sendo profundamente alterada, sendo portanto, Salvador um ponto de intercessão entre Goiás e África e não um centro de abastecimento. Por esse viés, a presença dos africanos em Goiás é abordada na perspectiva das trajetórias atlânticas em consonância com as transformações locais (LOIOLA, 2008, p. 22).
}

A forma de pagamento influenciou a vinda de escravos para o Estado de Goiás. Afinal, receber a fortuna cobrada por um escravo em ouro era mais atrativo que receber em açúcar, moeda de troca que estava em decadência no final do século XVIII, como afirma Loiola 
(2008). A descoberta do ouro no sertão atraiu de forma significativa os traficantes de escravos. Assim, vender escravos para os donos de minas no Brasil Central passou a ser mais lucrativo do que continuar vendendo-os para os senhores de engenho da Bahia.

Para alguns historiadores, mais um fator ocasionou o aumento de negros escravizados no sertão. Pois, "os escravos que fugiam do Maranhão, Pará e Pernambuco, buscavam refúgio nos cerrados do Brasil Central pelas facilidades de esconderijos devido à geografia local" (KARASCH, 1996 apud LOIOLA, 2008, p.27). A assertiva é que tanto pelo incentivo financeiro obtido pelos traficantes quanto por ser um lugar de difícil acesso e, favorecer o isolamento dos fugitivos, não há como negar que

o africano foi o elemento principal que possibilitou a colonização do vasto território goiano; com seu trabalho nas minas, abarrotava os cofres da Coroa Portuguesa (Inglaterra, França, etc), permitia abastança dos senhores e deitava na terra as sementes da sobrevivência do homem, implementando a lavoura que mais tarde floresceria. O africano ou afrobrasileiro foi o elemento civilizador (BAIOCCHI, 2013 , p. 28).

Nessa relação de conflitos entre escravizado e colonizador era necessário estabelecer estratégias de vigilância. O historiador Eliezer Cardoso Oliveira versa sobre o monitoramento feito aos cativos, "a direção do trabalho escravo foi (...) inconcebível sem feitores e capatazes de chicote em punho" (p. 5). Isso significa que o escravismo é inconcebível sem um elaborado sistema de vigilância e de punição. Nesse caso, para todo tipo de escravidão há sempre uma válvula de escape, isto é, os negros escravizados desenvolveram diversas formas de resistências. Por isso, trataremos a seguir sobre os quilombos e sua importância para os povos africanos e afrobrasileiros.

Há uma estreita relação entre o quilombo africano e o quilombo brasileiro. Pensando no quilombo de Palmares, ambos surgiram numa mesma época. Para Munanga (1996), a palavra Kilombo vem da língua banto e representa uma instituição sociopolítica militar que existia na África Central, mais especificamente no Zaire e Angola durante o século XVII. Os quilombos que foram formados no Brasil tiveram grandes contribuições dos povos banto.

Notifica-se que na África, com o decorrer do século XVIII, os povos aderiram ao sedentarismo, e partindo desse pressuposto Ratts (2000, p. 130) conceitua quilombo "enquanto grupo de escravos fugidos e local onde eles se instalavam". Nas Américas há 
grupos semelhantes, onde não há somente uma diversidade linguística, mas existem grupos que apesar de serem distintos, tanto em estrutura como período de sua existência, apresentam língua e cosmologia próprias.

No Brasil, durante o período escravista disseminou-se a ideia de que quilombo ou mocambo é um "reduto de negros escravos fugitivos" e, em 1974 foi definido pelo Conselho Ultramarino como "toda habitação de negros fugidos que passem de cinco, em parte despovoada, ainda que não tenham ranchos levantados nem se achem pilões neles" (CONSELHO ULTRAMARINO, 1740 apud. FERNANDES, 2014, p. 22) essa é uma visão totalmente estruturalista.

O conceito de quilombo apresentado como compreensão de quilombo histórico ${ }^{6}$ revela diversas perspectivas de análise, dentre elas destacamos que pode ser visto por dois aspectos. Por um lado, pelo olhar dos próprios negros escravizados, que se constituíam como organização social de resistência e como negação do sistema escravista que persistiu até 1888, ano em que ocorreu a lei de abolição, embora saibamos que na prática permaneceu ainda mais tempo.

De outro, pela face da concepção colonial, apresentada pelo Estado brasileiro até a proclamação da república em 1889, que procurava atender os interesses da elite escravocrata minando domínio dos negros fugidos. Com a abolição da escravidão já não havia mais as correntes, os troncos, os castigos físicos, mas, ainda assim os negros estavam presos à um processo doloroso que suprimia a sua identidade e as manifestações culturais com as quais conseguiam demonstrar um pouco de sua ancestralidade. Quebraram as correntes e aprisionaram a alma, dando-lhes uma liberdade condicionada, pois, não

havia lucro na derrocada do sistema escravista; em consequência organizaram movimentos abolicionistas e imigracionistas, assim matando dois coelhos com uma cajadada; livrando o país da mancha negra e alvejando a aparência da população (NASCIMENTO, 2002, p. 74-75)

\footnotetext{
${ }^{6} \mathrm{O}$ discurso historiográfico por muito tempo corroborou para simplificação das análises sobre a sociedade escravista no Brasil, omitindo conflitos internos ao sistema, bem como a estrutura social forjada pelos negros, buscando demonstrar homogeneização das relações sociais, restritas aos senhores (opressores) e negros escravizados (oprimido). É recente a escrita da história, a partir da década de 1970, que considera a complexidade do sistema escravista e busca abordar temas que ampliem esse campo de análise, apresentando negros e negras como sujeitos sociais (escravos libertos, quilombolas, mulheres negras, crianças, artesãos, comerciantes, pequenos agricultores) e sua resistência à escravidão, muitas vezes conquistada, configurando novos espaços de atuação na sociedade colonial (VELLOSO, 2006, p. 24).
} 
O termo quilombo é associado à expressão comunidade negra ou território negro. Tal reconhecimento vem paulatinamente com a construção de movimentos negros entre as décadas de 1970 e 1980. Em meio ao processo de "abertura política" estabelecido no final dos anos 1970, havia um conceito de quilombo definido como o reduto de escravizados fugitivos e o grande referencial era Palmares.

Paralelamente, já surgiam as informações sobre as comunidades negras rurais, ainda que pareça não ser tão explícito, visto o pouco registro sobre a temática entre os anos de 1979 e 1988, ano do centenário da Abolição da Escravatura no Brasil, quando começam a aflorar elementos para o debate sobre as comunidades negras rurais. No início dos anos 80, a Universidade de São Paulo desenvolveu um amplo projeto de pesquisa que abordou questionamentos sobre quilombo como sinônimo de isolamento.

Segundo, Borges Pereira (1983, p. 12),

a proposta central do projeto é a de pesquisar comunidades negras rurais incrustadas no meio rural brasileiro que, pelas características raciais ou étnicas de suas populações formando historicamente, como espécie de segmentos diferenciados ou não do que é tido e conhecido como o mundo do campesinato nacional. Tal tipo de proposta resulta, por assim dizer duas fontes de estímulo. Uma delas, facilmente identificada pelos que estão familiarizados com a bibliografia existente sobre o tema, é representada pela comprovada falta de trabalhos científicos sobre o negro brasileiro em ambiente rural. A segunda é mais sutil, pois insinua-se no horizonte de reflexão de sociólogos e antropólogos através de certa efervescência intelectual ligada a toda uma ideologia de auto-afirmação racial nucleada à ideia de quilombo expressão de sociedade igualitária e símbolo de identidade étnica para ideólogos e ativistas negros. Todo este processo de ideologização, decalcado em hipotéticas ou idealizadas expressões de cultura negra, filtra-se para o nível das preocupações críticas do cientista social como tema a exigir pesquisas sistemáticas.

Nesse caso, somente após o envolvimento de pesquisadores acadêmicos com o estudo da cultura negra e a construção de sua identidade é que se apresenta a percepção de quilombo com as formulações defendidas no âmbito do movimento negro. E, passa a ser identificado como um esforço vital para manter sua dignidade, buscando a liberdade através de fugas e organizando uma sociedade livre. Dessa maneira, inesperadamente, algo que era esporádico, rapidamente se tornou uma concepção constante sobre a vivência dos negros que recusaram a submissão e a violência do sistema escravista. 
A proliferação dos quilombos proporcionou aos negros uma simbologia de reunião fraterna, bem como de solidariedade, convivência, identidade existencial e principalmente representava além de um progresso humano, um progresso sociopolítico, por proporcionar igualitarismo econômico. Essa causa foi defendida pelo movimento negro e amplamente divulgada entre os intelectuais da época. Com a atuação do movimento negro veio algumas conquistas lavradas em leis.

Na visão contemporânea, o Decreto Lei 4.887 de 2003, no seu artigo $2^{\circ}$ diz:

consideram-se remanescentes das comunidades de quilombos, para fins deste decreto, os grupos étnicos raciais com trajetória histórica própria, dotados de relações territoriais específicas, com presunção de ancestralidade negra relacionada com a resistência à opressão histórica sofrida (BRASIL, DECRETO 4.887/2003).

Nesse mesmo decreto, no Artigo $3^{\circ}$ há a definição de que é o Instituto Nacional de Colonização e Reforma Agrária (INCRA) que "regulamenta os procedimentos administrativos para identificação, reconhecimento, delimitação, demarcação e titulação das terras ocupadas pelos remanescentes das comunidades dos quilombos”. Com essa concepção, a comunidade quilombola seria uma mera ocupação espacial, mas é necessário ressaltar que para ser considerado quilombola é preciso autodeclara-se pertencente de uma sociedade tradicional.

Antônio Carlos Santana Diegues (2001, p. 52) traz excelente contribuição ao sintetizar as características que uma comunidade precisa ter para ser quilombola.

a) Dependência e até simbiose com a natureza, os ciclos naturais e os recursos naturais renováveis a partir do qual se constrói um modo de vida;

b) Conhecimento aprofundado da natureza e de seus ciclos que se reflete na elaboração de estratégias de uso e de manejo dos recursos naturais. Esse conhecimento é transferido de geração em geração por via oral;

c) Noção de território ou espaço onde grupo social se produz econômica e socialmente;

d) Moradia e ocupação desse território por várias gerações, ainda que alguns membros individuais possam ter se deslocado para os centros urbanos e voltado para a terra de seus antepassados;

e) Importância das atividades de subsistência, ainda que a produção de "mercadorias" possa estar mais ou menos desenvolvida, o que implica numa relação com o mercado;

f) Reduzida acumulação de capital;

g) Importância dada à unidade familiar, doméstica ou comunal e às relações de parentesco ou compadrio para o exercício das atividades econômicas, sociais e culturais;

h) Importância das simbologias, mitos e rituais associados à caça, à pesca e atividades extrativas;

i) A tecnologia utilizada é relativamente simples, de impacto limitado sobre meio ambiente. Há uma reduzida divisão técnica e social do trabalho, sobressaindo o artesanal, cujo produtor (e sua família) domina o processo de trabalho até o produto final; 
j) Fraco poder político, que em geral reside com os grupos de poder dos centros urbanos;

k) Autoidentificação ou identificação pelos outros de se pertencer a uma cultura distinta das outras.

Essas características estão presentes em quase todas as literaturas da temática, sendo apresentada como parâmetro para o reconhecimento de uma comunidade remanescente.

Uma grande quantidade de negros viveram no Estado de Goiás durante o sistema escravista. Oliveira (2006) ao citar o historiador Palacín (1994) estima que em "1750 havia cerca de 20 mil escravos em Goiás" que, mesmo sendo submetidos à exploração e castigos diversos, trabalhavam principalmente nas minas contribuindo com a economia daquele período. Os castigos eram mais severos ainda se fossem pegos em momento de fugas ou capturados posteriormente.

As revoltas dos escravos eram constantes. E, apesar da vigilância do senhor e do feitor, muitos conseguiam fugir dos engenhos de açúcar e das fazendas. O senhor mandava atrás deles o capitão do mato e, quando eram apanhados e trazidos de volta, sofriam ainda maiores castigos. Por isso precisavam fugir cada vez mais para longe, para lugares onde não pudessem ser alcançados. E, quando conseguiam se reunir nesses lugares, precisavam se organizar muito bem para se defender dos brancos, caso eles chegassem até lá (OLIVEIRA 2001, p. 20).

Em algumas ocasiões até mesmo a acomodação era uma maneira de resistir e muitos escravos viviam de maneira "amigável" com seus senhores, podendo trabalhar, juntar riquezas, comprar alforrias, e até mesmo adquirir escravos. Mas aqueles que não aceitavam sua condição de escravo e conseguiam fugir se agrupavam em locais estratégicos, formando os quilombos goianos. Alguns historiadores estimam que exista mais de 70 comunidades quilombolas espalhadas pelo o estado.

Assim, cada comunidade expressa a sua diversidade cultural através das danças, festas religiosas, cultos aos ancestrais, culinária, dentre outros elementos que os constituem como um fenômeno cultural. De acordo com Neves (2007, p.19), o período aurífero em Goiás teve significativas contribuições dos quilombolas, porque,

embora muitos se envolvessem com assaltos, enquanto outros cuidavam de gado e produziam carne seca, outros negociavam com vizinho, guerreavam com índios, frequentemente para capturar suas mulheres e estabeleciam vários tipos de relações com a população livre de cor da fronteira. Dessa maneira, eles vieram a 
desempenhar um importante papel na formação de comunidades camponesas nos atuais estados de Goiás e Tocantins.

Essas relações, conforme afirma a autora, eram quase sempre conflituosas, o que intensificava o medo da população em relação aos escravos. Para Oliveira (2006, p. 34), “da parte dos negros, os brancos temiam as revoltas coletivas ou os ataques de negros fugidos que habitavam os quilombos das redondezas.

Entretanto, quando o assunto está relacionado à economia, se infere que além de sua contribuição com o trabalho nas minas, os negros eram aproveitados em outros afazeres, tais como as plantações e as colheitas ou atividades domésticas. Por isso, para (PALACIN, 1981) após a diminuição da exploração dos minérios, não havia interesse que os negros fossem libertos. Em Goiás, como nos outros estados, também dependia dessa mão de obra, porém com menos embate houve um remanejamento das atividades desenvolvidas pelos escravos.

Os poucos negros que obtinham sucesso em suas fugas formavam as comunidades quilombolas presentes no estado até os dias de hoje. Para Karasch (1996), era comum acontecerem tragédias relacionadas à formação de quilombos em Goiás, pois não tinham lideranças expressivas e nem eram ligados à movimentos abolicionistas que pudessem dar suporte às fugas. Eles eram penalizados pelos senhores brancos e pelos índios e, nos embates, muitos escravos que fugiam perdiam a vida ou voltavam para o cativeiro.

Portanto, pela busca por um lugar de refúgio e resistência, os negros fugitivos das minas, dos cativeiros e de outros lugares do país começavam a se organizar em grupos, formando os quilombos goianos entre eles encontra-se a Comunidade Quilombola Kalunga.

\section{Referências}

ALMEIDA, M. G., Territórios de quilombolas: pelos vãos e serras dos Kalunga de Goiás patrimônio e biodiversidade de sujeitos do Cerrado. Ateliê Geográfico. Edição Especial. Vol. 4, No 9 (2010) p. 36-63.

. O etnocentrismo e turismo nos Kalunga do nordeste de Goiás. In: LIMA, Ismar Borges (Org.) Etnodesenvolvimento e gestão territorial: comunidades indígenas e quilombolas. Curitiba: CRV, 2014, p. 195-212.

ALTMANN, Walter. Prefácio. In: REIMER, Haroldo. Liberdade Religiosa na História e nas Constituições do Brasil. São Leopoldo: Oikos, 2013, p. 7-10.

BAIOCCHI, Mar de Nasaré. Kalunga: povo da terra. $3^{\text {a }}$ ed. Goiânia: Editora UFG, 2013.

BERGER, P. L. O dossel sagrado: elementos para uma teoria sociológica da religião. $5^{\mathrm{a}}$ ed.

São Paulo: Paulinas, 2004. 
BERGER, Peter; LUCKMANN, Thomas. A construção social da realidade. $26^{\mathrm{a}}$ ed.

Petrópolis: Vozes, 1985.

BONOME, José Roberto. Cultura e Religião. Goiânia: Ed. PUC Goiás, 2010.

BORGES PEREIRA, J. B. Prefácio. In: BAIOCCHI, M. N. Negros de Cedro: um estudo antropológico de um bairro rural de Goiás. São Paulo: Ática, 1983, p. 10-15.

BURKE, Peter. Hibridismo Cultural. São Leopoldo, Unisinos, 2008.

CAMPBELL Joseph. O Poder do Mito. Tradução de Byl Moyer. São Paulo: Palas Athena, 1991.

CASSIRER, Ernest.. Linguagem e Mito. São Paulo: Perspectiva, 1985.

CENSO IBGE (2010). Disponível em:

$<$ http://www.ibge.gov.br/home/estatistica/populacao/censo2010/características_religiao_tab_ pdf.shtm>. Acesso em: 25 jul. 2016.

CHAUÍ, Marilena. Convite à filosofia. São Paulo: Ática, 2000.

CHAUL, N. A Construção de Goiânia e a Transferência da Capital. Goiânia: UFG, 1999.

CROATTO, José Severino. As Linguagens da Experiência Religiosa: uma introdução à fenomenologia da religião. Tradução Carlos Maria Vasquez Guitiérrez. São Paulo: Paulinas, 2001.

DELGADO, Lucília de A. N. História oral: memoria, tempo, identidade. Belo Horizonte. Autêntica, 2006.

DIEGUES, A.C. S. O mito moderno da natureza intocada. $3^{\text {a } e d . ~ S a ̃ o ~ P a u l o: ~ H U C I T E C, ~}$ 2001.

DOLOSTO, Cássius Dunk. Políticas Públicas e os Direitos Quilombolas no Brasil: O exemplo Kalunga. Rio de Janeiro: Lumen Juris, 2016.

FEITOSA, João (org.). Fragmentos da Nossa História: vitórias e conquistas de um povo. Goiânia: Karis, 2006.

FERNANDES, C. R., Os saberes e sabores da cultura Kalunga: origens e consequências das alterações nos sistemas alimentares. Dissertação de mestrado. Universidade de Brasília, Brasília - DF, 2014.

FURTADO, Rafael Nogueira. Ascese e racionalização: Weber, Foucault e o problema do controle da conduta. Universidade Federal de Sergipe. PROMETEUS - Ano 6 - Número 11Janeiro-Junho/2013.p. 187-225.

GEERTZ, Clifford. A Interpretação das Culturas. $1^{\text {o }}$ ed. Rio de Janeiro: LTC, 2008. Nova Luz Sobre a Antropologia. Rio de Janeiro: Jorge Zahar, 2001.

GUSDORF, G. Mito e Metafísica. São Paulo: Convívio, 1995. 
HALL, Stuart. Identidade cultural na pós-modernidade. Rio de Janeiro: DPeA, 2002.

Quem precisa de identidade? In: SILVA, Tomaz Tadeu et. al. (Org.) Identidade

e Diferença: a perspectiva dos estudos culturais. Petrópolis: Vozes, 2009, p. 103-135.

HOBSBAWM, Eric. Sobre história: ensaios. Tradução de Cid Knipel Moreira. São Paulo:

Companhia das Letras, 1998.

KARASCH, Mary. O quilombo do ouro na capitania de Goiás.In: GOMES, Flávio; REIS, João José (Orgs.) Liberdade por um fio: história do quilombo no Brasil. São Paulo:

Companhia das Letras, 1996.

KUPER. Adam. Cultura: a visão dos antropólogos. Bauru: Edusc, 2002.

LOIOLA, Maria Lemke. Trajetória atlântica, percursos para a liberdade: africanos e descendentes na capitania dos Guayaze. Dissertação (Mestrado em História). Universidade Federal de Goiás, Goiânia, 2008.

MARINHO, Thais Alves. Cultura Kalunga: entre a territorialidade e o culturalismo. In: LIMA, Ismar Borges (Org.) Etnodesenvolvimento e gestão territorial: comunidades indígenas e quilombolas. Curitiba: CRV, 2014, p. 155-178.

MOSCOVICI, Serge. A Representação Social da Psicanálise. Tradução Álvaro Cabral. Rio de Janeiro: Zahar, 1978.

MOTA, Rosiane Dias. Protestantismo, identidade territorial e territorialidades da comunidade quilombola. In: ALMEIDA, Maria Geralda (Org), O Território e a Comunidade Kalunga: quilombolas em diversos olhares - Goiânia: Gráfica UFG, 2015, p. 250-271.

NEVES, M. V. M., Festa do vão do Moleque: religiosidade e identidade étnico cultural. Dissertação (Mestrado em Ciências da Religião), Universidade Católica de Goiás, Goiânia, 2017.

OLIVEIRA, Eliezer Cardoso. As representações do medo e das catástrofes em Goiás. Tese (Doutorado em Sociologia), Universidade de Brasília, Brasília, 2006.

OLIVEIRA, Raquel (Org.) Uma história do povo Kalunga. Brasília: Ministério de Educação -MEC, 2001.

PALACIN, Luís. Fundação de Goiânia e Desenvolvimento de Goiás. Goiânia: Ed. Oriente, 1973.

PALACIN, L.; MORAIS M. S. Sociedade colonial:(1549 a 1599). Goiânia: UFG, 1981.

SILVA, M. J. Quilombos do Brasil Central: Violência e Resistência Escrava, Goiânia: Kelps, 2003.

SILVA, Tomaz Tadeu. A produção social da identidade e da diferença. In: SILVA, Tomaz Tadeu et. al. (Org.) Identidade e Diferença: a perspectiva dos estudos culturais. Petrópolis: Vozes, 2009, p. 73-103. 
SILVEIRA, João Paulo de Paula ; REIMER, Haroldo. Prolegômenos para uma história cultural das religiões. In: REIMER et. al. (Orgs.), Primeiros diálogos: uma introdução à reflexão histórica. São Leopoldo: OiKos, 2012, p. 61-72.

SOARES, P.S. Tecnologias e Saberes Africanos. In. MORAIS, C. C.P.; OLIVEIRA, L. F. et. al. (Org.), Educação quilombola. Goiânia: FUNAPE; UFG/CIAR, 2013.

VELLOSO, A. D. Uma análise do processo histórico-espacial da comunidade do Engenho II - Kalunga. Dissertação ( Mestrado em Gestão ambiental), Universidade de Brasília, Brasília: 2007.

WOODWARD, Kathryn. Identidade e diferença: uma introdução teórica e conceitual. In: SILVA, Tomaz Tadeu, et. al. (Org.) Identidade e Diferença: a perspectiva dos estudos culturais. Petrópolis: Vozes, 2009, p.5-72. 